International Journal of English Literature and Social Sciences
Vol-6, Issue-2; Mar-Apr, 2021

\title{
Psychoanalysis: Dream including Freudian Symbolism
}

\author{
Asst Prof. Aradhana Shukla
}

Department of English, S.S.D.G.PG College Rudrapur, Udham Singh Nagar, Kumaun University, Nainital, Uttarakhand, India.

Received: 06 Nov 2020; Received in revised form: 16 Jan 2021; Accepted: 06 Feb 2021; Available online: 06 Mar 2021 (C)2021 The Author(s). Published by AI Publication. This is an open access article under the CC BY license (https://creativecommons.org/licenses/by/4.0/).

\begin{abstract}
The initial acceptance of Psychoanalysis is the credence that all human posses memories, feelings, unconscious thoughts and desires. Jung felt that "The dream is a little hidden door in the innermost and most secret recesses of the psyche". Some psychologists think that dreams are nothing more than the result of unplanned brain pursuit that take place when we are sleeping, while others acquire the perspective of human such as Sigmund Freud and Carl Jung that dreams can release a human's deepest unconscious wishes and desires.
\end{abstract}

Keywords - Stimuli, Wish fulfillment, Regression, Infantile, Sigmund Freud, Carl Jung, Dream.

\section{INTRODUCTION}

Sigmund Freud was born as Sigismund SchlComo Freud (May 6, 1856), in the Moravian town of Freiberg in the Austro- Hungarian Empire. He was the son of Jakob Freud and Amalia Nathanson. He studied philosophy under the German philosopher, Franz Brentano; physiology under Ernst Brucke; and Zoology under the German zoologist, Cark Claus; likewise, he completed his graduation in 1881 with an MD. In 1885, Freud was appointed as a university lecturer in neuropathology. In 1885-86 he went to Paris for continuing his studies in neuropathology under the guidance of Jean-Martine Charcot at the Salpetriere Clinic. In 1886 Freud married Martha Bernays, grand daughter

Of a chief rabbi in Hamburg. In the same year, he set up his private practice. He used hypnosis in his clinical work and adopted Josef Breuer's approach, his collaborator, and as well as his friend.

They invited Ann $\mathrm{O}$ to talk about her symptoms while under hypnosis, in the course of which the symptoms reduced. He found that the patient's dreams could be analyzed to reveal the complex structuring of unconscious materials and to demonstrate the psychic action of repression which underlay symptom formation.

He used the term "Psychoanalysis" to refer to his new clinical method. During the development of these new theories, Freud experienced disturbing dreams, depression, and heart irregularities. He self-analyzed his dreams and memories of childhood. Some of his famous works are as follows-

- Studies on Hysteria (1895) which Freud coauthored with Josef Breuer and it described the evolution of his clinical methods.

- The Interpretation of Dreams (1899) considered being his ground-breaking masterpiece with introducing Freud's theory of the unconscious with respect to dream interpretation and provides an interpretation of Freud's dreams and the dreams of his patients in terms of wish-fulfillments.

- On Dream (1901) an abridged version of The Interpretation of Dreams.

- The Psychopathology of Everyday Life(1901)

- Jokes and their Relation to the Unconscious (1905)

- Three Essays on the Theory of Sexuality (1905)

- Introduction to Psychoanalysis (1916-17)

- Moses and Monotheism (1939) 


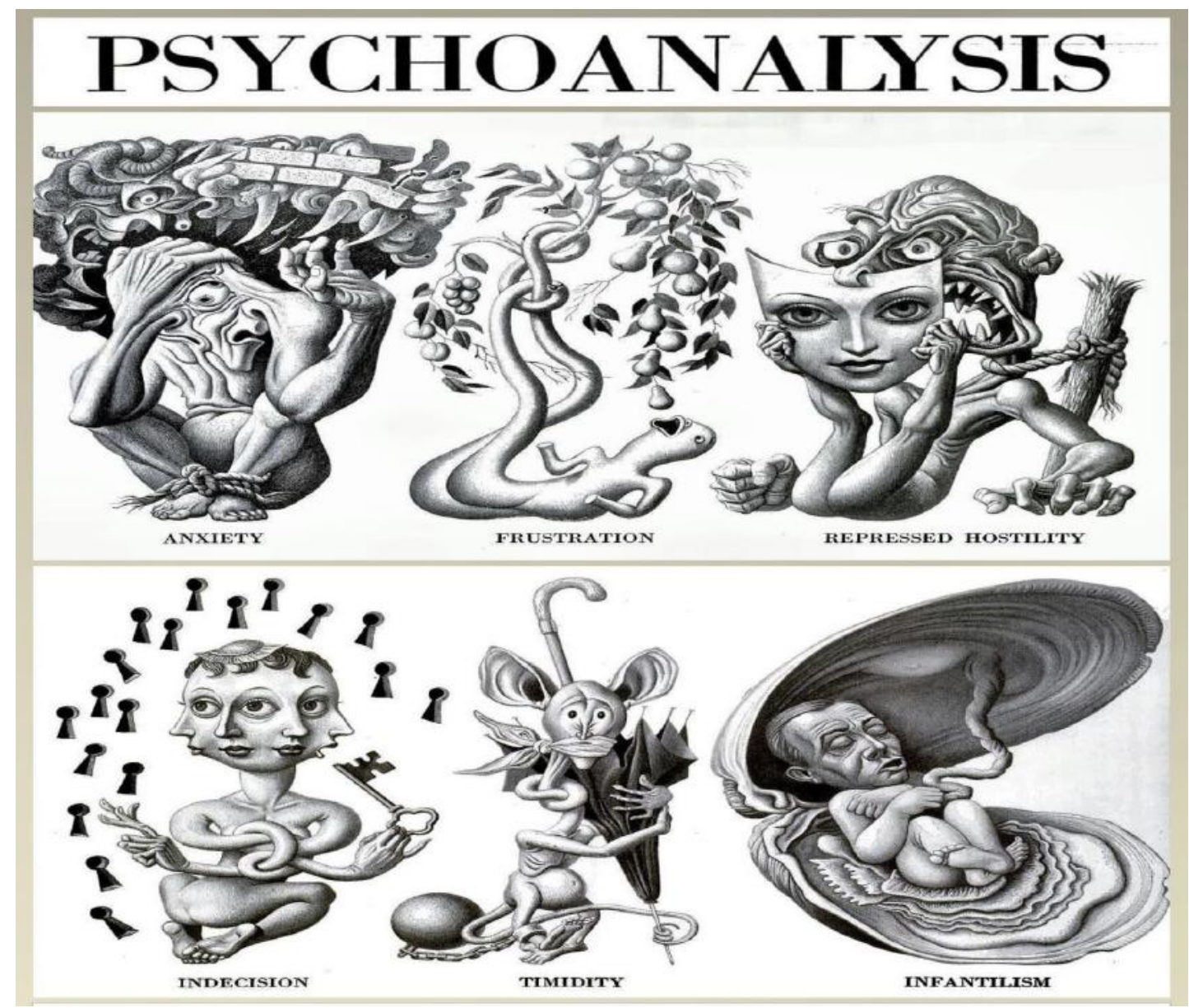

Fig.1: Symptoms of psychoanalysis

His works have been prominently admired such notions as the unconscious, defense mechanism, dream symbolism, and Freudian slips. He also made a longstanding footprint on the knowledge domain as literature, Marxist, literary criticism, philosophy, feminist theories, film, and psychology.

\section{MEANING OF DREAMS}

According to Sigmund Freud, "Dreams are the royal road to the Unconscious ".

\section{PSYCHOLOGY OF DREAMS}

"When the mind rests, the Unconscious mind whispers " 


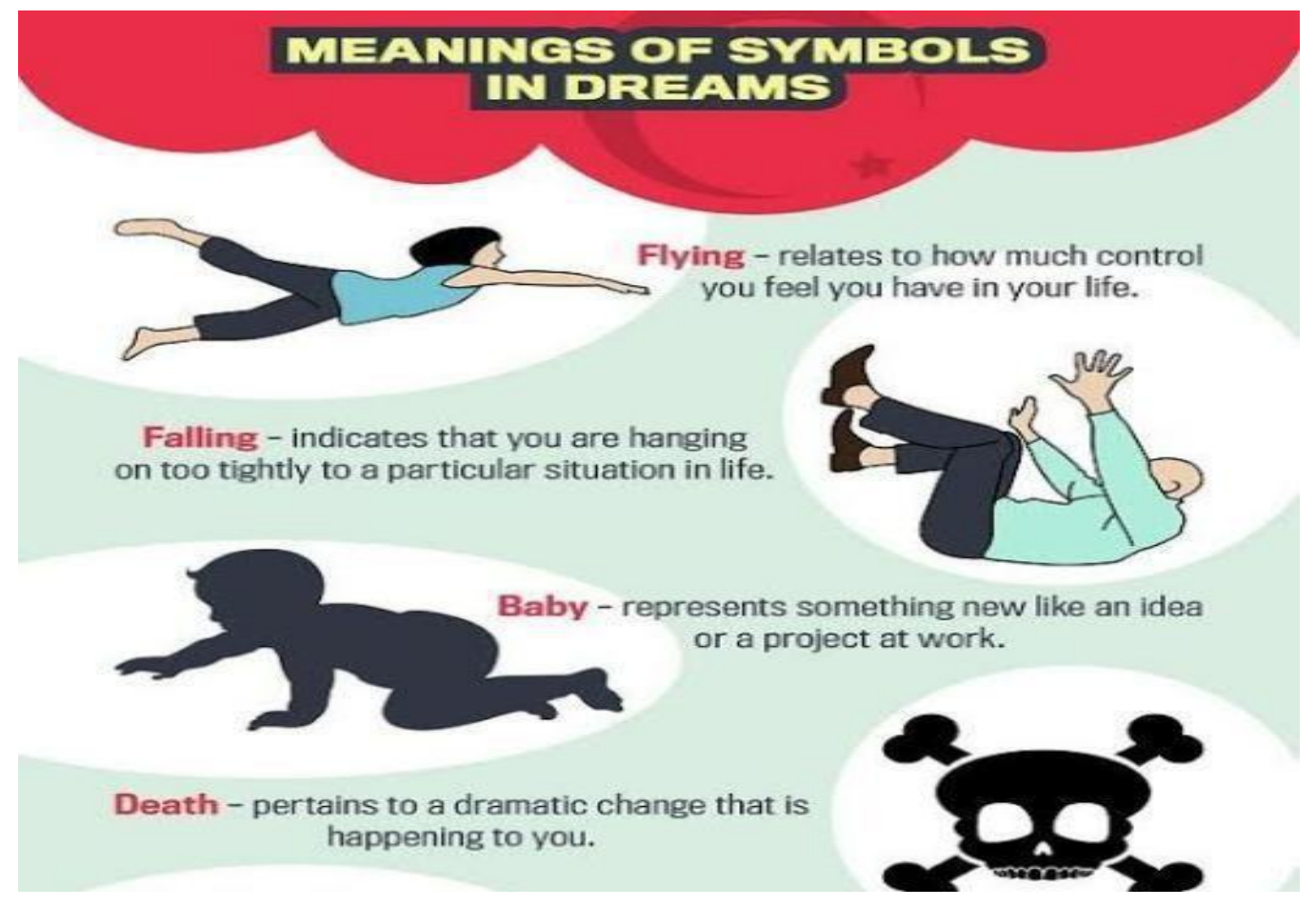

Fig. 2 Different meanings of symbols in dreams.

\section{FREUDIAN SYMBOLISM IN DREAM}

Freud, who has feasibly offended psychoanalysis as much as he has convinced it, produced a large number of novel symbolic translations to which no transition was given at first, but most of which were later established and had to be acquired. The ongoing experience of psychoanalysis has licensed us to discover patients who have displayed to a staggering extent have an instant grasp of dream symbolism. Here we shall enclose ourselves by saying that representation by a symbol comes under the heading of the indirect representation. Dream takes on this symbolism to give a disguised portrayal of their latent thoughts.

Now I shall include some exemplar of the use of such symbols, which will show how nonviable it is to arrive at the interpretation of a dream if one excludes dream symbolism. The two means of dream interpretation must supplement one another practically, as well as theoretically precedence is maintained by the latter subpoena which designates the final consequence to the opinion of the dreamer while the symbol- a translation which we undertake, plays a supplementary part.

- The hat is the symbol of aman.

- The little one is the genital organ being run over as a symbol of sexual intercourse.

- Representation of the genitals by buildings, stairs, and shafts.

- The male organ is symbolized by persons and the female by a landscape.

- Castration dreams of children.

- A modified staircase dream.

- The sensation of reality and the representation of repetition.

- The question of symbolism in the dreams of normal persons.

- Dream of a chemist. 


\section{HINDU DREAM SYMBOLISM}

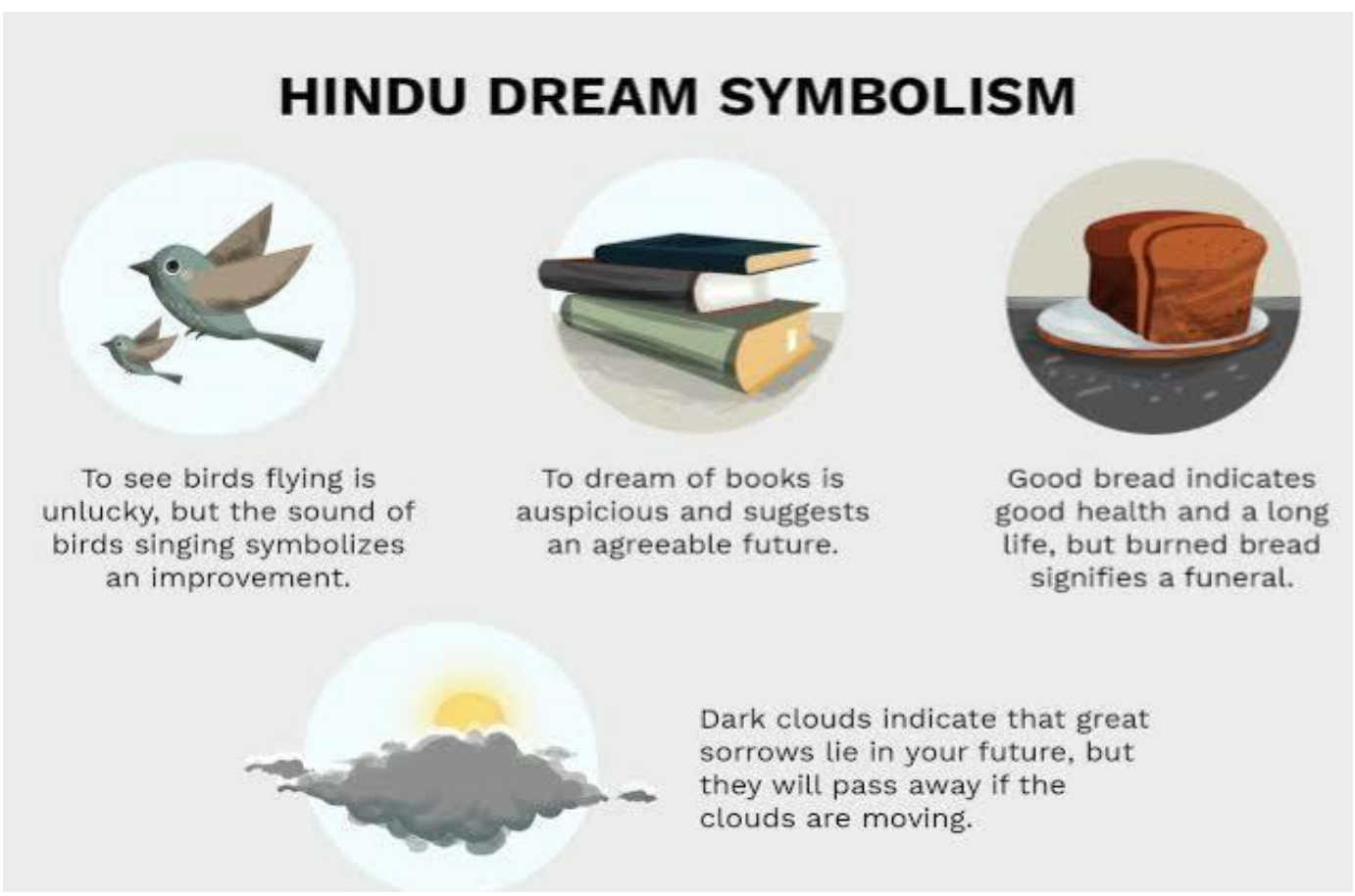

Fig.3 Symbolisms in Hindu dreams

As per Vedic Hindu Astrology, there is an idiosyncratic meaning of dreams in a discrete's life. There are different types of Vedic dreams interpretations of different dreams. Dreams have the power and are capable to provide an insight into the future of the person just like a window, according to Hindu spirituality and Religion. A dream is a sequence of images, ideas, emotions, and sensations that normally transpire involuntarily in the mind throughout specific phases of sleep. One and all dreams about some emotions, certain characters, some objects, specific situations, and of all symbolic images that must be deftly explicated to come out with an accurate image and probe. Few dreams are symbolic but act like a messenger of fortune and good luck whereas few bring negativity, remorse, sadness, and bad luck in life. Since the beginning of time, dreams have been there. Probably, it is the most asked question that whether dreams are important or not? Even though many of them the link that dreams are peripheral and have no sense to them. Research, experimentation, and Astrology prediction exhibit that there can be countless divergent interpretations and astrological sense of the dream. They are predominantly the "hallucinations of the sleeping mind". Dreams can also be immensely confusing, disturbing, strange, and even repetitive. This is all about that where the interpretation of dreams takes place into action.

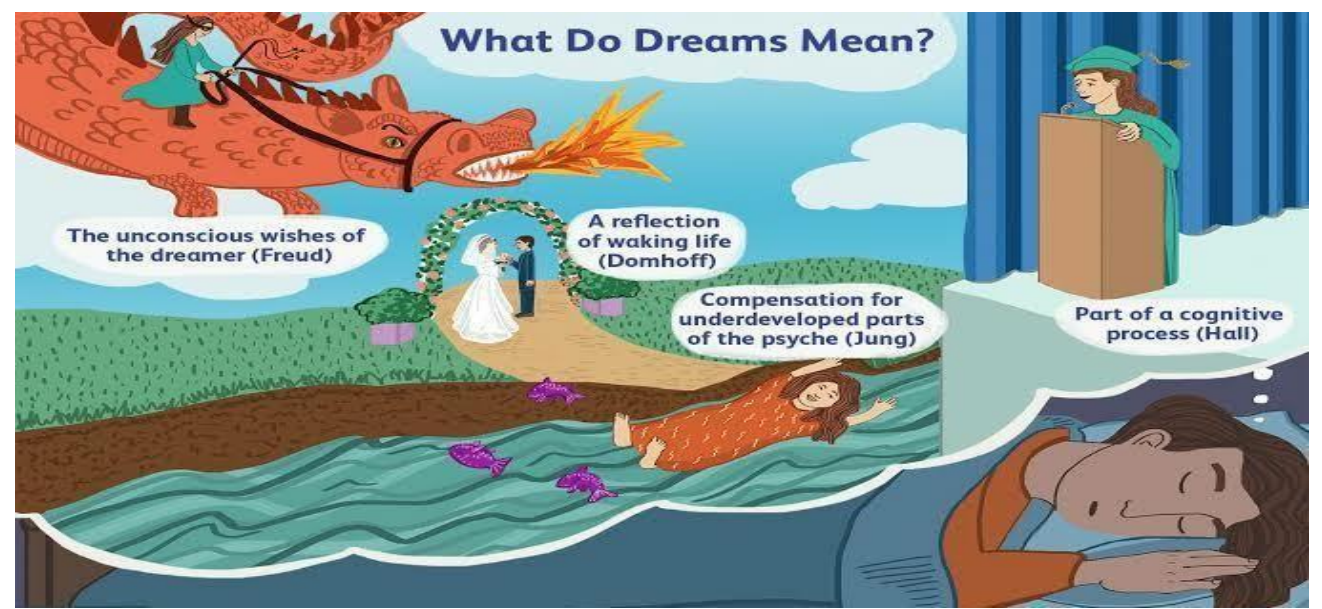

Fig. 4 Meaning of dreams 


\section{THREE THEORIES OF DREAMS}

\begin{tabular}{|l|l|l|}
\hline Theory & Basic Explanation & Meaning of Dream \\
\hline $\begin{array}{l}\text { Unconscious wish- } \\
\text { fulfillment theory (Freud) }\end{array}$ & $\begin{array}{l}\text { Dreams represent unconscious wishes, the dreamer } \\
\text { wants to fulfill }\end{array}$ & $\begin{array}{l}\text { Latent content reveals unconscious } \\
\text { wishes }\end{array}$ \\
\hline Dreams for survival theory & $\begin{array}{l}\text { Information relevant to daily survival is reconsidered } \\
\text { and reprocessed }\end{array}$ & $\begin{array}{l}\text { Clues to everyday concerns about } \\
\text { survival }\end{array}$ \\
\hline
\end{tabular}

\begin{tabular}{|l|l|l|}
\hline Activation synthesis theory & $\begin{array}{l}\text { Dreams are the result of random activation of various } \\
\text { memories, which are tied together in a logical } \\
\text { storyline }\end{array}$ & $\begin{array}{l}\text { Dream scenario that is constructed is } \\
\text { related to dreamer's concerns }\end{array}$ \\
\hline
\end{tabular}

\section{Dreaming Begins with "PGO Waves" \\ Brooks \& Bizzi (1963), after Jouvet, Michel, \& Courjon (1959)}

\section{- Implanted Microelectrodes}

- Cats, Rodents

- Activity During REM Sleep

- Not during SWS, Waking

- Sequential Activation

1. Pons

2. Lateral Geniculate Nucleus

3. Occipital Cortex

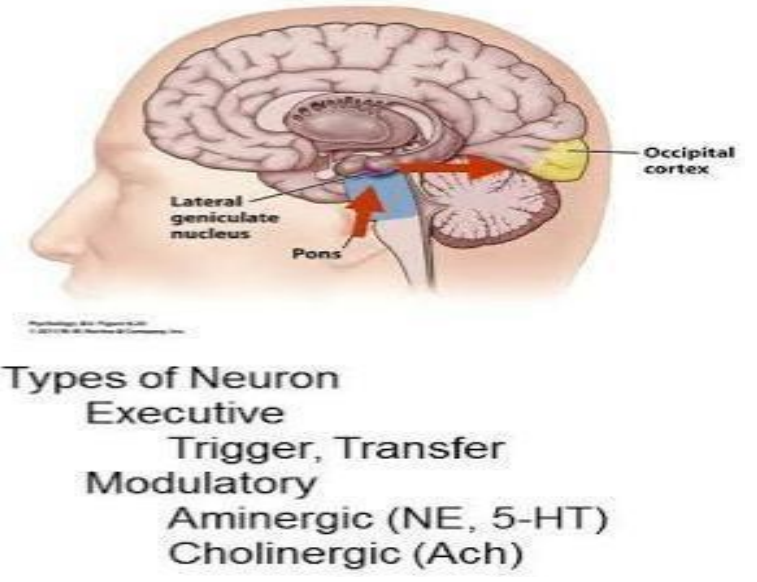

Fig. 5 PGO Waves description

\section{FIVE MAJOR CHARACTERISTICS OF DREAMS}

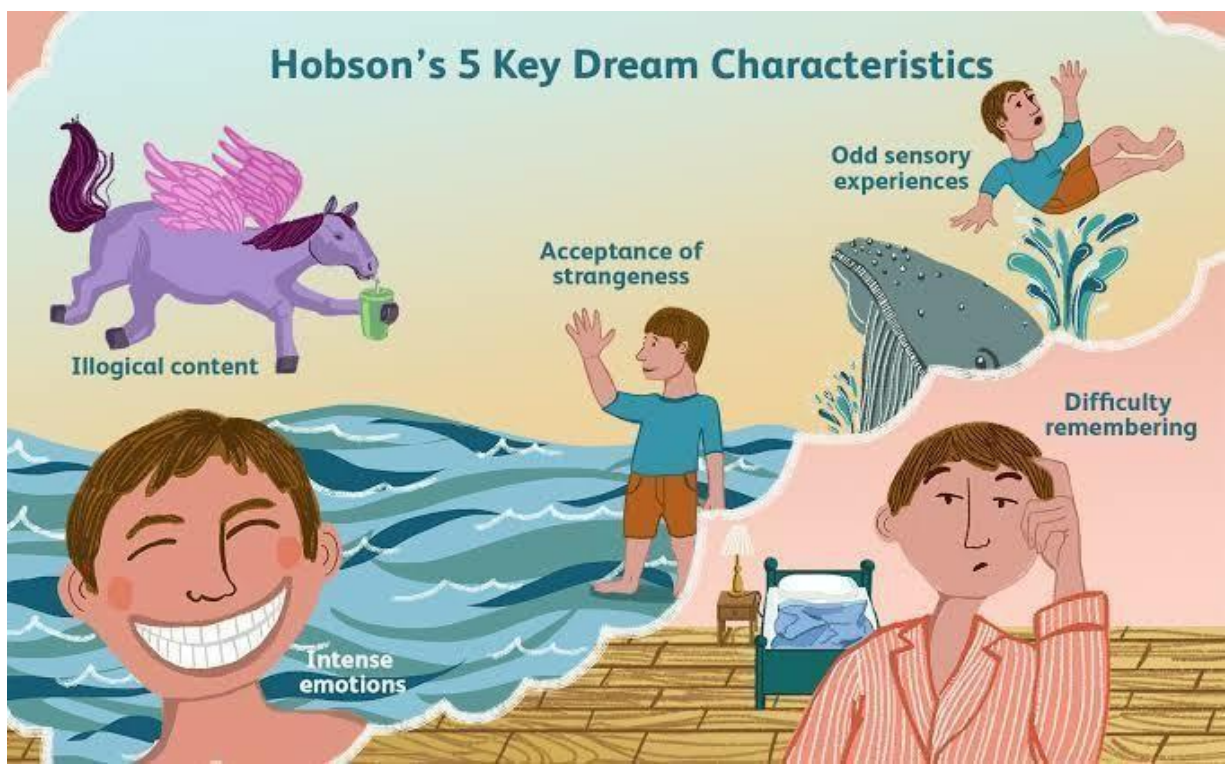

Fig.6 Hobson's dream characteristics 
Many artists, philosophers, and researchers have been enraptured by dreams for thousands of years but still, in history, dreams could not become the subject of serious scientific study. While dreams can fluctuate significantly. J. Allan Hobson in his book (The Dreaming Brain, 1988) pinpointed five fundamental aspects of dreams.

- Dreams often feature intense emotions.

- Dreams are frequently disorganized and illogical.

- $\quad$ Strange dream content is accepted without question.

- People often experience the bizarre sensations.

- Dreams are difficult to remember.

\section{CONCLUSION}

Concluding in the words of W. Stekel, through the analysis of some convincing examples he said that the part of the dream "dreamed" is again to be depreciated in value and robbed of its reality; that which the dreamer continues to dream after awakening from the dream within the dream is what the dream-wish desires to put in place of the extinguished reality. It may therefore be assumed that the part "dreamed" contains the representation of reality and the real reminiscence, while, On the other hand, the continued dream contains the symbol of what the dreamer wished. The inclusion of certain content in a "dream within the dream" is, therefore, equivalent to the wish that what has just been designated as a dream should not have occurred. The dream-work utilizes the dream itself as a form of deflection.

\section{ACKNOWLEDGEMENT}

It is an immense pleasure for me to assume this Research Article. I feel highly doing the research entitled "PSYCHOANALYSIS: DREAM INCLUDING FREUDIAN SYMBOLISM".

Here my special thanks goes to my Principal ma'am, Dr.Satvinder Kaur (H.O.D. Eng. Literature)who helped me in guiding for writing the research article and while writing, I really found lot of new points which enhance my knowledge much more than earlier.

Finally, I would like to thanks my family members also for their valuable support and encouragement. I completed this research article with full enthusiasm and by the deep of my heart.

\section{REFERENCES}

[1] Freud, Sigmund. The Interpretation Of Dreams. New Delhi: Prakash Books India Pvt.Ltd,2020.print.

[2] Freud, Sigmund. OnDreams. New York: Dover publications, INC.2016.print.

[3] Freud, Sigmund. A General Introduction to Psychoanalysis. New York: Horace Live rightINC.1920.print

[4] Www.Ncbi.Nlm.Nih.Gov.weiZhang,23Aug,2018,www.nc bi.nlm.nih.gov/pmc/articles/PMC6115518.

[5] Www.Verywellmind.com,KendraCherry,7Apr2020,www. verywellmind.com/the-interpretation-of-dreams-bysigmund-freud-2795855.

[6] Www.Psychologytoday.Com.FrankT.McAndre,www.psyc hologytoday.com/us/blog/out-the-ooze/2018/01/thefreudian-symbolism-in-your-dreams.Accessed1Jan.2018.

[7] www.simplypsychology.org/psychoanalysis.html

[8] www.futurepointindia.com/article/en/an-encyclopaedia-ofhindu-dream-interpretation-symbolisms-and-meanings9223 